\title{
Tax Burden and the Mismeasurement of State Tax Policy
}

\author{
W. Robert Reed \\ University of Canterbury, New Zealand \\ Cynthia L. Rogers \\ University of Oklahoma
}

\begin{abstract}
Tax Burden, defined as the ratio of total tax revenues over personal income, is frequently used to measure state tax policy. The authors analyze the empirical relationship between changes in Tax Burden and changes in tax policies from 1987 to 2000 using states' forecasts of revenue impacts of new tax legislation. Their two major findings have important implications. First, they demonstrate that income-induced, nontax policy changes are a significant determinant of changes in Tax Burden. These income effects are likely to cause misinterpretation when Tax Burden is used as a variable in economic growth regressions. Second, they estimate that approximately half of the total variation in Tax Burden is due to changes in nontax policy factors. This finding quantifies the extent of the "mismeasurement" problem that has been discussed, but not analyzed, in previous literature. In concluding, the authors promote the use of alternative approaches for estimating the economic effects of taxes.
\end{abstract}

Keywords: tax policy; fiscal policy; Tax Burden; state economic development; tax rates

\section{Introduction}

Conclusive evidence concerning the empirical relationship between state tax policy and economic growth continues to be elusive in the academic literature. Typically the relationship is analyzed by regressing an outcome measure of interest (such as per capita personal income) on a tax policy

Authors' Note: An earlier draft of this article was presented at the University of Oklahoma and at the 2003 National Tax Association meetings. We thank the participants for their helpful comments. We also are indebted to Kevin Grier, David Merriman, Dan Sutter, and Steve Yamarik for helpful comments and suggestions. 
variable. The resulting coefficient estimate is commonly used to advise policy makers regarding the impact of tax policy proposals. The validity of this interpretation depends crucially on the accuracy with which the tax policy variable is measured.

Good measures of tax policy are difficult to construct from statutory tax parameters due to substantial variation in "state tax base definitions, rate structures and enforcement practices" (Helms 1985, 577). As a result, most of the state and local economic development literature measures tax rates with the variable Tax Burden, defined as the ratio of state (or state and local) tax revenues to personal income (Wasylenko 1997, 42). ${ }^{1}$

The literature widely acknowledges that Tax Burden may be an imprecise measure of tax policy. Because of this wide recognition, researchers often omit discussions of this potential imprecision (e.g., Yamarik 2000; Tomljanovich 2004). Empirical studies of growth continue to proxy state tax policy with Tax Burden because of its ease of availability and the lack of better alternatives. ${ }^{2}$ This is regrettable, because this approach can lead to the misinterpretation of empirical results and bad policy advice.

If movements in Tax Burden are driven by nontax policy factors that are correlated with the outcome measure, then the resulting coefficient estimates cannot be use to predict impacts of potential tax policy changes. Theory suggests that this scenario is quite plausible: If state tax systems are nonproportional, then changes in state income will induce changes in Tax Burden. If the dependent variable is also income-related, then an empirical relationship that has nothing to do with tax policy will be generated between Tax Burden and the dependent variable.

This study investigates how well Tax Burden measures state tax policy. We make several contributions. First, we empirically quantify the relationship between changes in Tax Burden and changes in state tax policy. Following previous research, we use state-generated forecasts of revenue impacts associated with new tax legislation as direct measures of state tax policy. These serve as a proxy for changes in tax revenues due to changes in tax policy, holding constant the influence of other variables (like income).

We further contribute to the literature by evaluating sources of divergence between Tax Burden and state tax policy. We decompose changes in Tax Burden into three mutually exclusive components: (1) changes in state tax policy, (2) income-induced changes that are independent of tax policy, and (3) changes caused by other factors that are independent of state tax policy. We demonstrate the statistical significance of incomeinduced changes in explaining variations in Tax Burden. 
Finally, we use our theory-driven empirical results to estimate the percentage of variation in Tax Burden that is due to nontax policy factors. Our preferred estimates indicate that approximately half of the variance in the change of Tax Burden is due to factors other than state tax policy. Our results are important for researchers and policy makers interested in the effect of tax policy on economic growth. By empirically identifying the substantial imprecision associated with using Tax Burden as a proxy for state tax policy, we highlight the need for better measures.

The article proceeds as follows. Section 2 identifies two data series that, we argue, provide objective and reliable measures of state tax policy. Section 3 presents qualitative evidence that Tax Burden mismeasures state tax policy. Section 4 derives a theoretical model relating our Tax Burden variable to state tax policy and other factors. Section 5 presents the empirical results including estimates of the degree to which changes in Tax Burden are driven by nontax policy factors. Section 6 concludes with suggestions for future research.

\section{Direct Measures of State Tax Policy}

To determine whether Tax Burden is a reliable measure of state tax policy, we need to track and quantify changes in state tax policy. Total tax revenues will not work, since these follow the business cycle, even when tax policy does not change. Our approach employs the actual revenue forecasts used by states to assess the consequences of new tax legislation.

State laws generally require the budgetary impacts of tax and spending legislation to be estimated. This information is collected by two national organizations - the National Association of State Budget Officers (NASBO) and the National Conference of State Legislatures (NCSL). Both organizations began conducting annual surveys of their membership regarding state tax policy in 1987.

NASBO, in conjunction with the National Governors' Association, collects its information from state budget officers. ${ }^{3}$ Among other things, respondents provide estimates of changes in the next fiscal year's tax revenues resulting from changes in tax legislation. NCSL collects its information from state legislative staff. ${ }^{4}$ Historically, NCSL has used two methods to report tax change impacts. The baseline method (NCSL-B), available as an annual time series from 1987 to 1997, tracks tax legislation changes adopted in a given year in terms of the impact on the following fiscal year. It was discontinued in favor of the taxpayer liability method (NCSL-TL), 


\section{Figure 1}

\section{A Comparison of Three Measures of State Tax Policy Changes: NASBO, NCSL-B, and NCSL-TL}

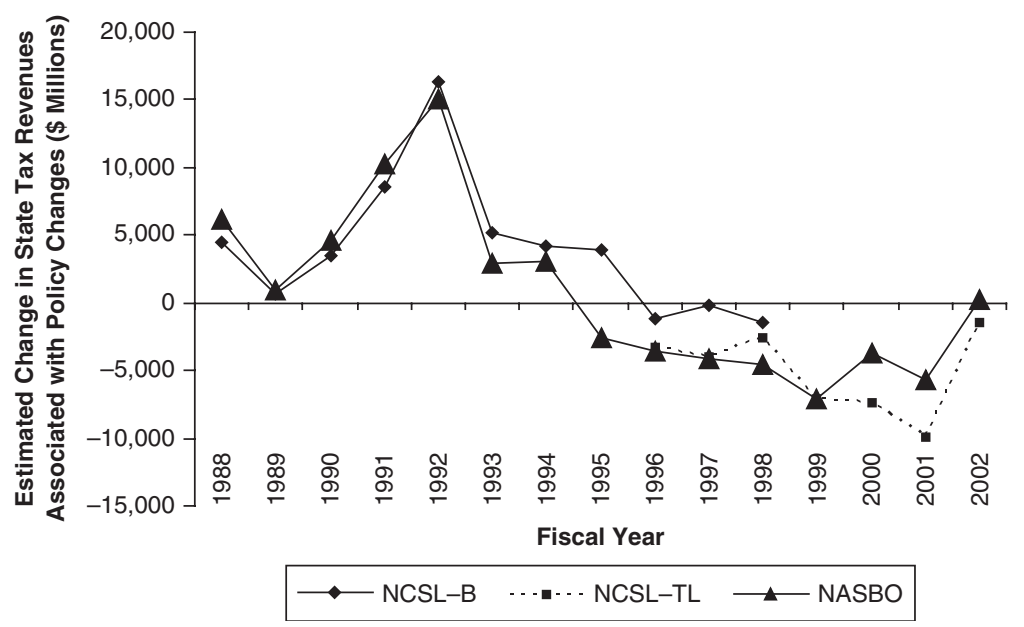

Note: NASBO $=$ National Association of State Budget Officers; NCSL $=$ National Conference of State Legislatures. The figure plots the annual sum of state tax changes as estimated by the NASBO, NCSL-B and NCSL-TL measures. NCSL-B and NCSL-TL refer to NCSL's "Baseline" and "Tax Liability" measures. The three measures are described in the text. Fiscal year refers to fiscal year when tax changes are estimated to take effect.

which was initiated in 1995. The NCSL-TL series provides estimates of changes in the taxes actually paid by taxpayers. ${ }^{5}$

In addition to definitional variations concerning the implementation of tax changes, the NASBO and NCSL surveys also differ with respect to when information is collected. Revisions in revenue forecasts may not be picked up by both surveys. Figure 1 compares the NASBO- and NCSLcollected state revenue forecasts associated with tax policy changes. Fiscal year represents the year that the tax changes are legislated to take effect. Despite some differences, the overall impression is that the different series present similar pictures of predicted revenue changes attributed to state tax policy changes. ${ }^{6}$ The sample correlation between the two series is .777 and is highly significant. When these series are converted to measures of 
tax policy as discussed in the next section, their correlation rises to .822 . In contrast, pairwise correlations between each of these measures and Tax Burden are substantially lower at .384 (NASBO) and .398 (NCSL). ${ }^{7}$

We take as our point of departure that the forecasts collected by NASBO and NCSL represent unbiased estimates of the revenue impacts of changes in state tax policy. Corroborating support for employing this assumption comes from three sources: (1) previous research on strategic bias in state revenue forecasts; (2) personal conversations with professional staff at NASBO, NCSL, and state budgetary offices; and (3) the use of these series in recent studies.

Although no studies directly evaluate the accuracy of state revenue forecasts associated with tax legislation, some studies have investigated state forecasts of total tax revenues. ${ }^{8}$ No conclusive evidence of bias has been found. ${ }^{9}$ Even if states strategically bias total revenue forecasts, however, this bias would not necessarily extend to revenue forecasts of specific tax legislation. These latter forecasts are likely to be more closely scrutinized than overall budget forecasts since they are inputs in the legislative process and impact specific economic groups. As such, they need to be credible to many different constituencies. ${ }^{10}$ Personal conversations with current and former professionals from NASBO, NCSL, and several state budgetary offices provided anecdotal confirmation that the survey responses supplied by the states are untainted by strategic bias.

Finally, we note that several recent studies have employed the NASBO and NCSL-collected revenue forecasts as direct measures of state tax policy. In particular, Poterba (1994), Poterba and Rueben (2001), and Maag and Merriman (2003) used NASBO data. Merriman (2001) used both series to predict changes in tax legislation.

\section{Qualitative Evidence of State Tax Policy Mismeasurement}

In the analysis that follows, we define the variable Tax Burden as the ratio of state (but not local) tax revenues $(R)$ over personal income $(Y)$,

$$
\text { Tax Burden }{ }_{s t}=R_{s t} / Y_{s, t-1} \text {. }
$$

We exclude local tax revenues to be consistent with the NASBO- and NCSLcollected estimates. We take the relationship between this restricted version of Tax Burden and state tax policy as an indication of the relationship 
between that of the more broadly defined Tax Burden variable and state and local tax policy. Note that tax revenues are reported by fiscal year, while state personal income is measured over the calendar year. Following convention, personal income is from the calendar year that spans the beginning of the fiscal year. ${ }^{11}$

As a starting point, we compare the Tax Burden time series with the NASBO and NCSL-B time series for fiscal years 1988 to $2001 .^{12}$ For a few states (e.g., Iowa), the Tax Burden series seems reasonable as measures of state tax policy: it rises during years in which tax legislation was projected to increase state revenues, declines during years in which tax legislation was projected to decrease state revenues, and stays the same when no change in revenues was expected. A careful examination of the Tax Burden series for all the states, however, reveals that this is the exception, not the rule.

Figures 2 and 3 illustrate two typical scenarios in which Tax Burden mismeasures state tax policy. In Figure 2, large projected increases in Louisiana's taxes in 1989 had little effect on the state's Tax Burden. Furthermore, during the early 1990s, tax increases corresponded with a general decline in the Tax Burden series. In contrast, Figure 3 shows large movements in Michigan's Tax Burden from 1988 through 1994 despite the negligible forecasted impacts of tax policy changes. Cases like Louisiana where significant changes in state tax policy correspond with little, or even perverse, movement in Tax Burden; and Michigan, where large movements in Tax Burden are not generated by changes in tax legislation, are common. ${ }^{13}$

Figure 4 aggregates data from all the states to present an overall picture of how well changes in Tax Burden correspond to changes in state tax policy. ${ }^{14}$ According to both the NASBO and NCSL-B measures, states legislated increases in tax revenues on net every year between 1988 and 1994. Yet the value of Tax Burden in 1994 was about the same as it was in 1988. States lowered taxes on net every year from 1996 to 2001 . However, except for fiscal year 2001, these tax cuts are not evident in the corresponding Tax Burden series. Clearly, Tax Burden does not accurately track changes in state tax policies.

\section{Theoretical Analysis Relating Tax Burden and State Tax Policy}

\subsection{The Decomposition of Tax Burden}

This section models the relationship between Tax Burden and state tax policy to clarify the empirical link. Following the literature, the relationship 


\section{Figure 2}

\section{Tax Burden versus Changes in State Tax Policy: Louisiana}

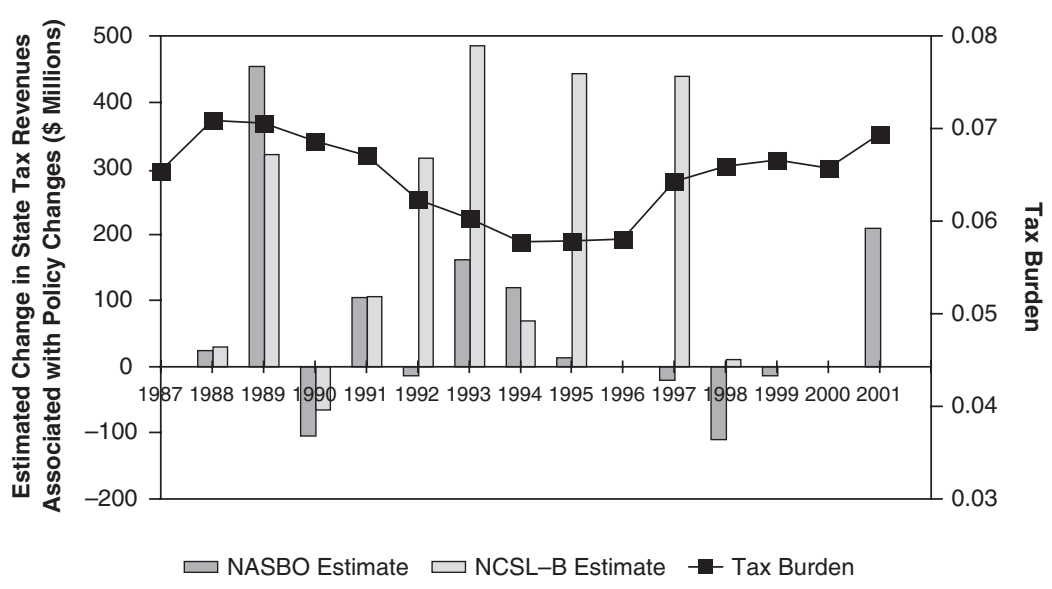

Note: The National Association of State Budget Officers (NASBO) estimates run through 2002, while the National Conference of State Legislatures-Baseline (NCSL-B) estimates only extend through 1998. Tax Burden measures the ratio of total state tax revenues over total state personal income.

between a state's tax revenues $(R)$ and its income $(Y)$ is approximated with a linear revenue function: ${ }^{15}$

$$
R_{s t}=\beta_{0, s t}+\beta_{1, s t} Y_{s, t-1}+\varepsilon_{s t}^{R},
$$

where $\varepsilon_{s t}^{R}$ is a mean-zero error term assumed to be uncorrelated with state income. Thus, tax policy for state $s$ at time $t$ can be characterized by the parameters $\left(\beta_{0, s t}, \beta_{1, s t}\right)$, where $\beta_{1, s t}$ is the state's effective marginal tax rate on income at time $t$.

A "true" measure of the revenue change caused by a change in state tax policy parameters in fiscal year $t$, which shows up in fiscal year $t+1$ revenues, should hold income constant. This can be specified as follows,

$$
\Delta \text { Taxes }_{s t}^{\text {True }}=\Delta \text { Taxes }\left._{s t}\right|_{Y}=\Delta \beta_{0, s t}+\Delta \beta_{1, s t} \cdot Y_{s, t-1},
$$




\section{Figure 3}

\section{Tax Burden versus Changes in State Tax Policy: Michigan}

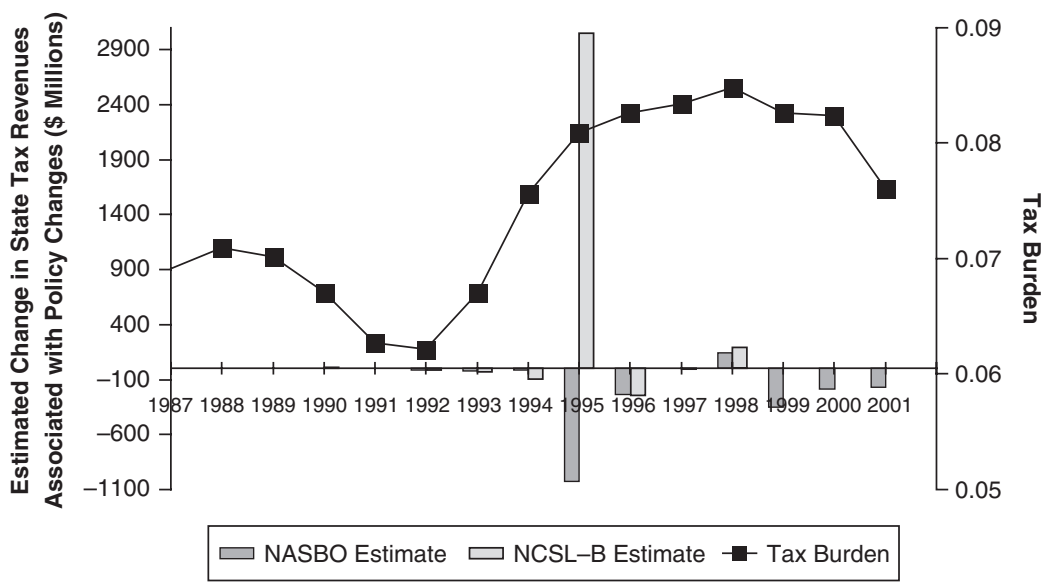

Note: The National Association of State Budget Officers (NASBO) estimates run through 2002, while the National Conference of State Legislatures-Baseline (NCSL-B) estimates only extend through 1998. Tax Burden measures the ratio of total state tax revenues over total state personal income.

where $\Delta \beta_{0, s t}$ is the component of tax changes that does not change with a state's income, and $\left(\Delta \beta_{1, s t} \cdot Y_{s, t-1}\right)$ is the component of tax changes that are affected by a state's income.

Let us consider measuring the change in state tax policy by the change in Tax Burden,

$$
\Delta \text { TaxBurden }_{s t}=\text { TaxBurden }_{s, t+1}-\text { TaxBurden }_{s t}=\frac{R_{s, t+1}}{Y_{s t}}-\frac{R_{s t}}{Y_{s, t-1}} .
$$

Substituting equation (2) into equation (4), the relationship can be expressed as

$$
\Delta \text { Tax Burden }_{\mathrm{st}}=\Delta \beta_{1, s t}+\left(\frac{\beta_{0, s t+1}}{Y_{s t}}-\frac{\beta_{0, s t}}{Y_{s, t-1}}\right)+\left(\frac{\varepsilon_{s, t+1}^{R}}{Y_{s t}}-\frac{\varepsilon_{s t}^{R}}{Y_{s, t-1}}\right) .
$$

Clearly, changes in state income $\left(Y_{s, t}, Y_{s, t-1}\right)$ can cause changes in Tax Burden even when there is no corresponding change in state tax policy 
Figure 4

Tax Burden versus Changes in State Tax Policy: United States

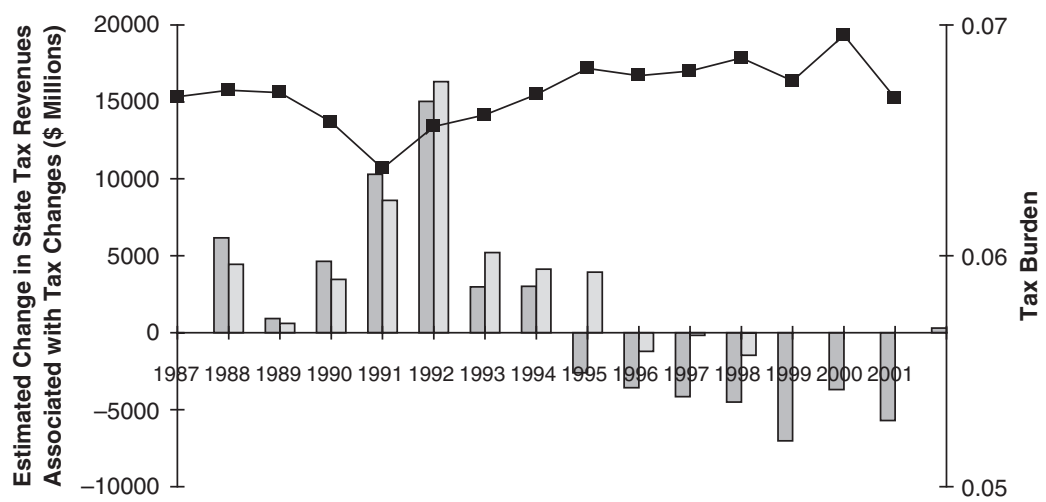

Note: The National Association of State Budget Officers (NASBO) estimates run through 2002, while the National Conference of State Legislatures-Baseline (NCSL-B) estimates only extend through 1998. Tax Burden measures the ratio of total state tax revenues over total state personal income.

parameters $\left(\beta_{0, s t}=\beta_{0, s t+1}, \Delta \beta_{1, s t}=0\right) .{ }^{16}$ As we shall subsequently demonstrate, this is not the only problem associated with using Tax Burden to measure the impact of changes in tax policy.

Substituting equation (3) into (5) yields the following:

$$
\Delta \text { TaxBurden }_{s t}=\frac{\Delta \text { Taxes }_{s t}^{\text {True }}}{Y_{s, t-1}}+\beta_{0, s t+1}\left(\frac{Y_{s, t-1}-Y_{s t}}{Y_{s, t-1} Y_{s t}}\right)+\eta_{s t},
$$

where $\eta_{s t}=\left(\frac{\varepsilon_{s, t+1}^{R}}{Y_{s t}}-\frac{\varepsilon_{s t}^{R}}{Y_{s, t-1}}\right), E\left(\eta_{s t}\right)=0$, and $\eta_{s t}$ is heteroscedastic and autocorrelated. 
Equation (6) decomposes the change in Tax Burden into three components. The first term is the change in Tax Burden due to the change in state tax policy. The second term represents the change in Tax Burden due to changes in income. The third term is composed of miscellaneous factors that are unrelated to state tax policy. The latter two terms cause Tax Burden to mismeasure state tax policy. Estimation of equation (6) would provide an indication of the extent of this measurement error. Unfortunately, the policy variable $\Delta$ Taxes $_{s t}^{\text {True }}$ is unobserved.

In the remainder of this section, we devise a strategy to estimate the components of Tax Burden as a function of observable variables. Our key insight consists of identifying the relationship between $\Delta$ Taxes $_{s t}^{\text {True }}$ and the state revenue forecasts associated with tax policy changes collected by NASBO and NCSL. A complication that we need to address is that these latter forecasts incorporate changes in income, whereas $\Delta$ Taxes $_{s t}^{\text {True }}$ consists of income-constant revenue changes.

\subsection{A Consistent Estimator of Tax Policy Using State Forecasts}

Let the variable $\Delta$ Taxes $_{s t}^{\text {Forecast }}$ represent the NASBO/NCSL-collected forecasts of the revenue change at time $t+1$ attributed to a tax policy change at time $t$. In the context of the model above,

$$
\Delta \text { Taxes }_{s t}^{\text {Forecast }}=\Delta \beta_{0, s t}+\left(\Delta \beta_{1, s t} \cdot Y_{s t}^{F}\right)
$$

where $\Delta \beta_{0, s t}$ is the component of tax changes that does not change with a state's income, ${ }^{17} Y_{s t}^{F}$ is the forecasted value of state income for the next year, and $\left(\Delta \beta_{1, s t} \cdot Y_{s t}^{F}\right)$ is the component of tax changes that are affected by a state's income. ${ }^{18}$

We make two assumptions to express $\Delta$ Taxes $_{\text {st }}^{\text {True }}$ as a function of observables. First, we assume that $\Delta \beta_{0, s t}=0$. It follows from equations (3) and (7) that

$$
\frac{\Delta \text { Taxes }_{s t}^{\text {True }}}{Y_{s, t-1}}=\frac{\Delta \text { Taxes }_{s t}^{\text {Forecast }}}{Y_{s t}^{F}} .
$$

Note that previous studies estimating marginal tax rates impose the additional assumption of a linear revenue function that does not vary over 
time, that is, $\Delta \beta_{1, s t}=0$, (e.g., Koester and Kormendi 1989; Becsi 1996). In comparison, our approach is less restrictive. There is an additional reason to support the assumption that $\Delta \beta_{0, s t}=0$ : as a practical matter, the effect of this assumption is small. The appendix demonstrates that under reasonable assumptions, the error associated with measuring $\Delta$ Taxes $_{s t}^{\text {True }}$ using states' forecasts of tax policy changes when $\Delta \beta_{0, s t} \neq 0$ will generally be less than 5 percent.

Our second assumption is that the relationship between the realized and forecasted values of state income is given by

$$
Y_{s t}=\left(1+\varepsilon_{s t}^{F}\right) Y_{s t}^{F}
$$

where $\varepsilon_{s t}^{F}$ represents the percentage difference between the income forecast developed by state budgeters and the realized value of state income, and $E\left(\varepsilon_{s t}^{F}\right)=0 .{ }^{19}$

Substituting Equation (9) into Equation (8) produces the following relationship,

$$
\frac{\Delta \text { Taxes }_{s t}^{\text {Forecast }}}{Y_{s t}}=\frac{\Delta \text { Taxes }_{s t}^{\text {True }}}{Y_{s, t-1}}+v_{s t},
$$

where $v_{s t}=-\frac{\Delta \text { Taxes }_{s t}^{\text {Forccast }}}{Y_{s t}} \cdot \varepsilon_{s t}^{F}$, $v_{s t}$ is heteroscedastic, and $\underset{T \rightarrow \infty}{\operatorname{plim}}\left(\sum_{t=1}^{T} \frac{\mathrm{v}_{s t}}{T}\right)=0$. Thus, the ratio of the observed variables $\Delta$ Taxes $_{s t}^{\text {Forecast }}$ and $Y_{s t}$ is a consistent estimate of the change in state tax policy in the sense that $\sum_{t=1}^{T} \frac{\Delta \text { Taxes }_{\text {st }}^{\text {Forcast }}}{Y_{\text {st }}} / T$ is arbitrarily close to $\sum_{t=1}^{T} \frac{\Delta \text { Taxes }_{s t}^{\text {Tue }}}{Y_{s, t-1}} / T$ for sufficiently large $T \cdot{ }^{20}$

Using this consistent estimator of the unobserved variable $\Delta \operatorname{Taxes}_{s t}^{\text {True }} / Y_{s, t-1}$ as a proxy in equation (6) yields the following estimable regression equation:

$$
\begin{aligned}
\Delta \text { Tax Burden }_{s t}=\alpha_{0} & +\alpha_{1} \cdot \frac{\Delta \text { Taxes }_{s t}^{\text {Forecast }}}{Y_{s t}} \\
& +\alpha_{2, s}\left(\frac{Y_{s, t-1}-Y_{s t}}{Y_{s, t-1} Y_{s t}}\right)+\omega_{s t},
\end{aligned}
$$

where $\alpha_{2, s}$ is a state-specific coefficient estimating $\beta_{0, s}{ }^{21}$ The estimation is at best suggestive, since $\Delta$ Taxes $_{\text {st }}^{\text {Forecast }} / Y_{s t}$ measures $\Delta$ Taxes $_{s t}^{\text {True }} / Y_{s, t-1}$ with error (cf. equation [10]). 


\section{Estimation of the Tax Burden and State Tax Policy Relationship}

\subsection{Estimation of Equation (11)}

Columns (1) and (2) of Table 1 report the results of estimating equation (11) using the NASBO- and NCSL-collected state revenue forecasts, respectively. The NASBO data consist of 658 annual observations of 47 states over the years 1987 to $2000 .^{22}$ The NCSL data consist of 517 observations of the same 47 states over the years 1987 to 1997 . Coefficients are estimated using ordinary least squares (OLS) with robust standard errors. We use the "White period robust coefficient variance estimator" (Quantitative Micro Software 2004, 854) to accommodate both arbitrary serial correlation and time-varying variances in the error terms. This is appropriate given the error structure defined by equation (6) above.

The first explanatory variable in the NASBO- 1 and NCSL- 1 specifications is $\Delta$ Taxes $_{s t}^{\text {Forecast }} / Y_{s t}$, which we demonstrated to be a consistent estimator of state tax policy. Both the NASBO and NCSL specifications indicate that $\Delta$ Taxes $_{s t}^{\text {Forecast }} / Y_{s t}$ is positively and significantly associated with $\Delta$ Tax Burden. The $t$-values are quite high: 10.00 and 8.77 , respectively. This result is consistent with equation (11) and provides evidence that $\Delta$ Tax Burden captures, at least in part, the effects of actual state tax policy.

It is not unexpected that both of the estimated coefficients are less than 1 (0.5872 and 0.5578 , respectively) given that $\Delta$ Taxes $_{s t}^{\text {Forecast }} / Y_{s t}$ measures state tax policy with error. Although designed to measure the same impacts, the NASBO and NCSL revenue forecasts are imperfectly correlated (the sample correlation of the two series is .777). This is testimony to the difficulty of accurately measuring the revenue impacts of tax legislation. Nevertheless, the empirical results using these two different measures are quite similar, and continue to be so in subsequent specifications reported below.

Equation (11) also predicts that $\Delta$ Tax Burden will reflect changes in factors not related to tax policy. Of particular interest are the forty-seven state-specific interaction terms (corresponding to the term $\alpha_{2, s}$ $\left.\left(\frac{Y_{s, t-1}-Y_{s t}}{Y_{s, t-1} Y_{s t}}\right)\right)$, which reflect the influence of changes in state income not associated with state tax policy. Although we do not report the forty-seven individual coefficient estimates $\left(\hat{\alpha}_{2, s}\right.$ 's) due to space constraints, approximately three-fourths are individually significant at the 5 percent level. We test the hypothesis that these forty-seven coefficients are jointly equal to zero, corresponding to a test that Tax Burden is unaffected by nontax 


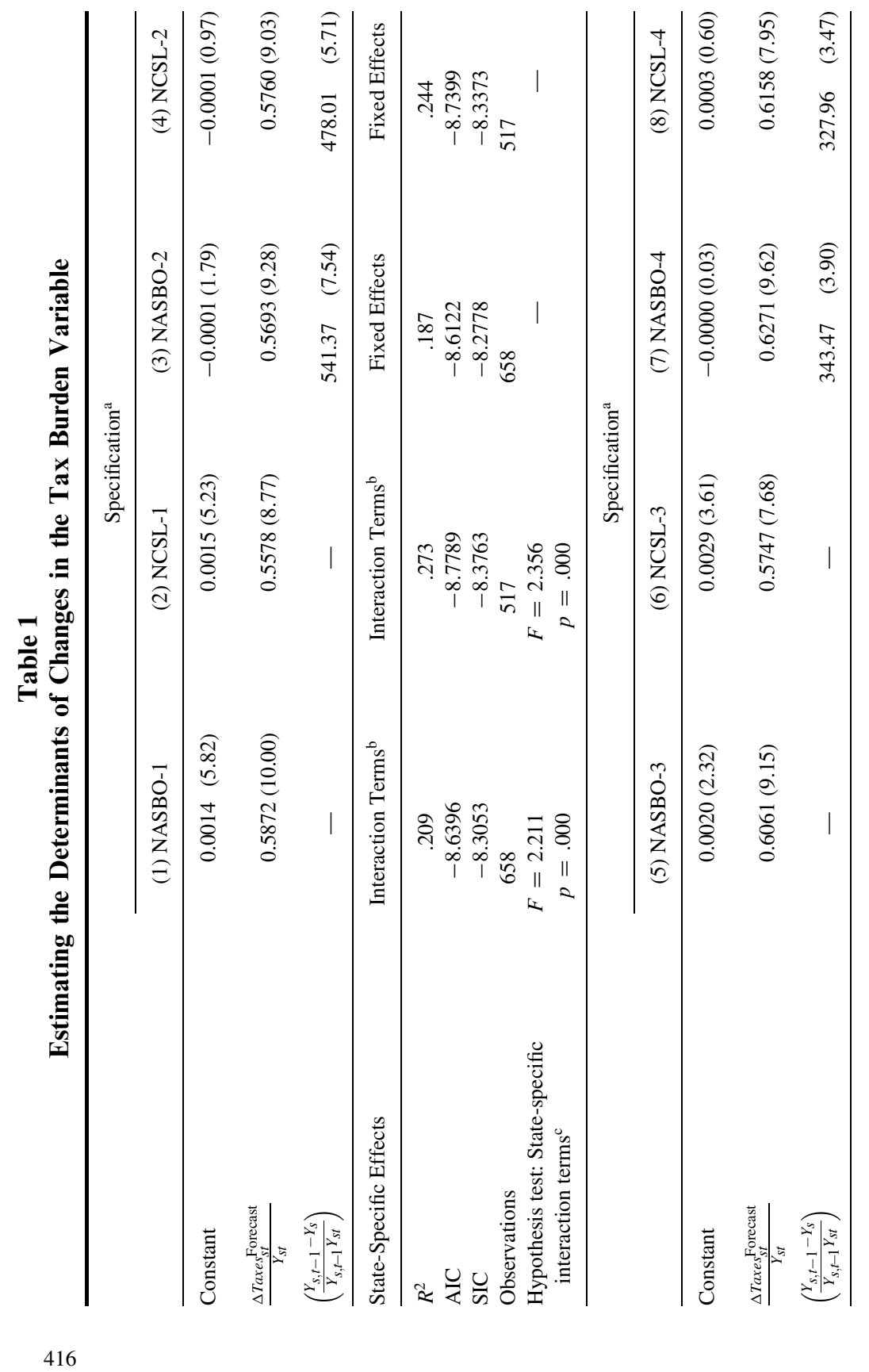




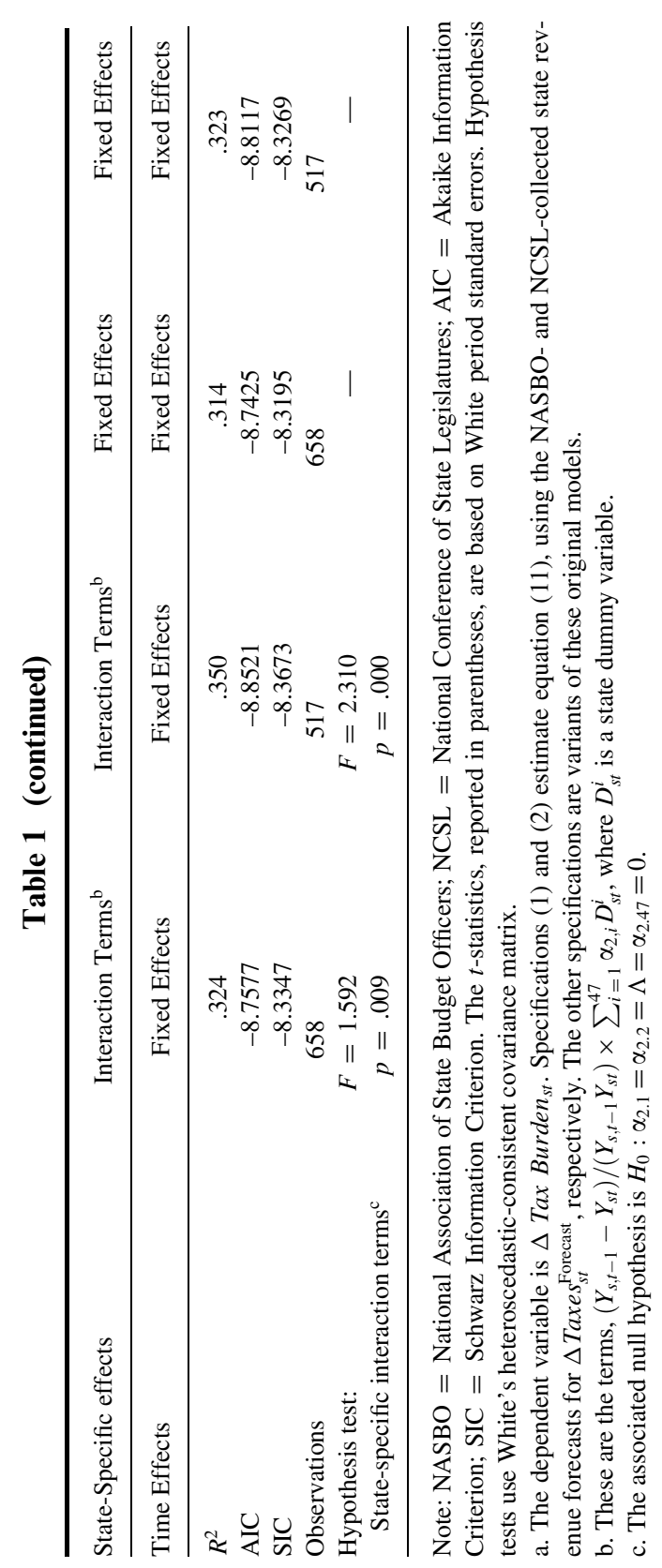


policy-related movements in state income. The results are reported at the bottom of columns (1) and (2) in Table 1. The hypothesis is soundly rejected in both specifications, with $p$-values well below .01 percent (cf. "Hypothesis Test: State-Specific Interaction Terms" in Table 1). These results provide empirical evidence that changes in state income induce significant movement in the Tax Burden variable, causing the Tax Burden variable to change even when there has been no change in state tax policy.

The results of columns (1) and (2) in Table 1 also provide suggestive evidence of the influence of other, nontax policy related factors. Recall that the error term in equation (11), $\omega_{s t}$, represents all other factors that can cause Tax Burden to mismeasure tax policy. The more important these factors are, the larger the error term and the lower the $R^{2}$ of the equation. In fact, both specifications are characterized by low $R^{2}$ values: .209 and .273 , respectively. Of course, this is only suggestive, since other factors, such as using an imperfect measure for $\Delta$ Taxes $_{s t}^{\text {True }} / Y_{s, t-1}$, would also depress $R^{2}$.

Although the theory of equation (11) specifies the change in income terms to be interacted with state-specific dummy variables, this specification is admittedly unorthodox. It raises concerns that the significance of these terms may be spurious, reflecting the influence of (omitted) statefixed effects. To address this concern, the equations in columns (1) and (2) of Table 1 were respecified by including the $\left(\frac{Y_{s, t-1}-Y_{s t}}{Y_{s, t-1} Y_{s t}}\right)$ term without interactions and adding state-fixed effects separately. The results are reported in columns (3) and (4) as specifications NASBO-2 and NCSL-2.

To compare these (nonnested) specifications, we employ two model selection criteria. The Akaike Information Criterion (AIC) and the Schwarz Information Criterion (SIC). Lower criterion values represent "better" models. Both the AIC and SIC criteria select the specifications of columns (1) and (2) of Table 1 over those of columns (3) and (4), respectively. In other words, the unorthodox specifications that arise from the theory are preferred to the more usual, fixed effects specification. This provides corroborating evidence in favor of the theory.

We perform one additional robustness check: Figure 4 suggests that Tax Burden is characterized by cyclical behavior. Accordingly, we add timefixed effects to the specifications of columns (1) through (4) of Table 1 and repeat our analysis. The results are reported in specifications (5) through (8). ${ }^{23}$

The AIC and SIC conclusions regarding whether the addition of timefixed effects improves the specifications are somewhat different. Based on 
the AIC, time-fixed effects always improve the specification. In contrast, based on the SIC, only the NASBO specifications are improved by the addition of time-fixed effects. As a practical matter, however, our main results

are unaffected: (1) the estimated coefficient on the $\Delta$ Taxes $_{s t}^{\text {Forecast }} / Y_{s t}$ variable is approximately equal to 0.6 across all specifications; (2) the hypothesis that the state-specific interaction terms have coefficients equal to zero is always soundly rejected; and (3) the theory-driven specifications are always preferred to the ad hoc, state-fixed effects specifications.

\subsection{The Importance of Nontax Policy Factors on Tax Burden}

The preceding analysis finds statistically significant relationships between the Tax Burden variable and both tax policy and nontax policy variables. From a mismeasurement perspective, we really would like to know how much of the movement in Tax Burden is due to factors other than state tax policy. This section takes three approaches to answering this question.

The first approach estimates a simple regression model with $\Delta$ Tax Burden as the dependent variable and $\Delta$ Taxes $_{\text {st }}^{\text {Forecast }} / Y_{s t}$ as the single explanatory variable. The $R^{2}$ from this equation provides an estimate of how much of the variance of $\Delta$ Tax Burden is due to state tax policy. It follows that $1-R^{2}$ provides an estimate of how much of the variance is due to nontax policy factors. The results from this analysis are reported in the first row of Table 2. Approximately 87.1 percent of the variance of $\triangle T a x$ Burden cannot be "explained" by the NASBO-measured tax policy variable, $\Delta$ Taxes $_{\text {st }}^{\text {Forecast }} / Y_{s t}$, and can correspondingly be attributed to nontax policy factors. The corresponding value is 84.1 percent when we use the NCSL-measure of state tax policy.

One problem with this simple approach is that the estimate of the effect of tax policy may be biased by the omission of other variables from the regression equation. Our second approach addresses this problem by employing the NASBO-3 and NCSL-3 specifications from Table 1, which include a large number of control variables. To isolate the effect of tax policy, we use the estimated coefficients from these specifications, fix the other variables in the equation at their sample means, and then obtain predicted values for $\Delta$ Tax Burden. The variance in these predicted $\Delta$ Tax Burden values allows us to compute the percentage of the total variance in $\Delta T a x$ Burden that can be attributed to changes in state tax policy. It follows that the remaining variance becomes an estimate of the amount of variation in $\Delta$ Tax Burden that can be attributed to nontax policy factors. The results 


\section{Table 2 \\ Estimating the Importance of Nontax Policy Factors as Determinants of Tax Burden}

\begin{tabular}{|c|c|c|c|}
\hline Approach & Description & NASBO & NCSL \\
\hline $1^{\mathrm{a}}$ & $\begin{array}{l}\text { Percentage variance of Tax Burden "explained" by nontax } \\
\text { policy factors (no control variables) }\end{array}$ & 87.1 & 84.1 \\
\hline $2^{b}$ & $\begin{array}{l}\text { Percentage variance of Tax Burden "explained" by nontax } \\
\text { policy factors (with control variables, } \\
\left.\beta_{\left(\frac{\Delta \text { Taxe }}{Y_{s t}^{\text {Forceast }}}\right)}=\hat{\beta}_{\left(\frac{\Delta \text { Taxesststecast }}{Y_{s t}^{\text {For }}}\right)}\right)\end{array}$ & 84.1 & 81.8 \\
\hline $3^{c}$ & $\begin{array}{l}\text { Percentage variance of } \Delta \text { TaxBurden "explained" } \\
\text { by nontax policy factors (with control variables, } \\
\beta_{\left(\frac{\left.\Delta \text { Taxes }_{S_{s t}^{\text {Forcast }}}\right)}{Y_{s t}}=1\right)}\end{array}$ & 56.8 & 44.9 \\
\hline
\end{tabular}

Note: NASBO $=$ National Association of State Budget Officers; NCSL $=$ National Conference of State Legislatures.

a. $\Delta$ TaxBurden is regressed on $\Delta$ Taxes $_{s t}^{\text {Forecast }} / Y_{s t}$. The "percentage variance 'explained' by nontax policy factors" is $1-R^{2}$ from this regression.

b. The estimated coefficients from the NASBO -3 and NCSL -3 specifications of Table 1 are used to construct predicted values for $\Delta$ TaxBurden. The "percentage variance 'explained' by nontax policy factors" equals 1 minus the ratio of the variance in these predicted values over the total sample variance of $\triangle$ TaxBurden.

c. This is similar to the previous approach, except that $N A S B O-3$ and $N C S L-3$ specifications are reestimated with the restriction that the coefficient on $\Delta$ Taxes $_{s t}^{\text {Forecast }} / Y_{s t}$ equals 1 . These (restricted) coefficient estimates are then used to construct predicted values for TaxBurden.

from this analysis are reported in the second row of Table 2. Based on the NASBO estimates of state tax policy, this approach leads to an estimate that 84.1 percent of the variance in $\triangle$ Tax Burden is due to nontax policy factors. The corresponding value using the NCSL estimates is 81.8 percent.

One can also find fault with this second approach. Measurement error in the NASBO and NCSL estimates is expected to cause the estimated coefficient of $\Delta$ Taxes $_{s t}^{\text {Forecast }} / Y_{s t}$ to be biased towards zero. This would dampen the predicted effect of tax policy on $\triangle$ Tax Burden and lead to an underestimation of the portion of $\Delta$ Tax Burden attributable to state tax policy. We address this problem by imposing the restriction from equation (6) that the coefficient on the tax policy variable should equal one. Restricted OLS estimation of the NASBO-3 and NCSL-3 models produces consistent estimates of the other coefficients in the equation, subject to the restriction being true. These coefficient estimates are then used to generate predicted values of $\Delta$ Tax Burden, again fixing the other variables in the equation at their mean levels. 
Forcing the coefficient on $\Delta$ Taxes $_{s t}^{\text {Forecast }} / Y_{s t}$ to equal one serves to greatly increase the amount of variation in $\Delta$ Tax Burden "explained" by state tax policy. Correspondingly, this decreases the amount "explained" by nontax policy factors. The third row of Table 2 gives estimates of the latter. Using this third approach, we find that nontax policy factors "explain" 56.8 percent of the variance of $\triangle$ Tax Burden using the NASBO data and 44.9 percent of the variance of $\triangle$ Tax Burden using the NCSL data.

If we take the calculations from this third approach as our preferred estimates, we are still left with the conclusion that a large portion of the movement in the Tax Burden variable, roughly half of its variance, is due to factors that are unrelated to state tax policy. This is consistent with the qualitative evidence presented in Figures 1 through 4.

\section{Conclusion}

This article investigates whether the variable Tax Burden, widely used in empirical studies of taxes and economic growth, reliably measures state tax policy. We have some good news: our findings indicate that changes in Tax Burden are positively and significantly related to changes in state tax policy. Unfortunately, we also find evidence of substantial measurement error.

We decompose Tax Burden changes into three components: (1) changes in state tax policy, (2) income-induced changes in revenue that do not measure state tax policy, and (3) other factors that do not measure state tax policy. The latter two categories constitute measurement error with respect to measuring state tax policy. Our empirical analysis establishes the quantitative and statistical importance of the second component. In other words, we demonstrate that changes in state income cause Tax Burden to change even when there has been no change in policy. This is of particular concern because many studies that attempt to measure the impact of taxes use an income-based dependent variable. Income-generated movement in the Tax Burden variable will induce a correlation between it and the dependent variable that is unrelated to state tax policy.

Last, our theoretical framework allows us to estimate the importance of nontax policy factors as determinants of changes in Tax Burden. Our preferred estimates indicate that approximately half of the variance in changes in Tax Burden is due to nontax policy factors. This constitutes a serious concern for those who rely on Tax Burden to provide an accurate measure of state tax policy. 
Our findings should be of particular interest to researchers and policy makers interested in measuring the effects of state tax policy. On a positive note, this study demonstrates how state revenue forecasts can be used to construct consistent measures of state tax policy. These forecast data will become increasingly attractive as the respective time series lengthen over time.

In the meantime, instrumental variables remain a potentially fruitful way to address measurement error bias in Tax Burden. Statutory tax parameters (e.g., property and sales tax rates, including information on the tax base; income tax rate parameters, including bracket and tax credit data) are obvious candidates for instruments. In addition, researchers may find it useful to pursue alternative methodologies for measuring and estimating tax effects such as representative agent models (e.g., Fisher and Peters 1998) and new, quasi-experimental methods (e.g., Reed and Rogers 2003, 2004).

\section{Appendix \\ The Error Associated with Measuring $\Delta$ Taxes $_{s t}^{\text {True }} / Y_{s, t-1}$ with $\Delta$ Taxes $_{s t}^{\text {Forecast }} / Y_{s t}$ When $\Delta \beta_{0, s t} \neq 0$}

Define the error associated with measuring $\Delta$ Taxes $_{s t}^{\text {True }} / Y_{s, t-1}$ with $\Delta$ Taxes $_{s t}^{\text {Forecast }} / Y_{s t}$ when $\Delta \beta_{0, s t} \neq 0$ by

$$
\text { Error }=\frac{\left(\frac{\Delta \text { Taxes }_{s t}^{\text {Forecast }}}{Y_{s t}^{F}}\right)-\frac{\Delta \text { Taxes }_{s t}^{\text {True }}}{Y_{s, t-1}}}{\frac{\Delta \text { Taxes }_{s t}^{\text {True }}}{Y_{s, t-1}}} .
$$

Substituting equations (3) and (7) into (A1) and performing some algebraic manipulation yields

$$
\text { Error }=\frac{\Delta \beta_{0, s t}\left(\frac{Y_{s t}^{F}}{Y_{s, t-1}^{F}}\right)-\Delta \beta_{0, s t}}{\left(\Delta \beta_{0, s t}+\Delta \beta_{1, s t} \cdot Y_{s, t-1}\right)} .
$$

Note that when $\Delta \beta_{0, s t}=0$, Error $=0$.

Define $k_{s t}$ such that

$$
\Delta \beta_{0, s t}=k_{s t} \cdot\left(\Delta \beta_{1, s t} Y_{s, t-1}\right) .
$$


Thus, if $k_{s t}=1$, the component of total new taxes that is independent of state income, $\Delta \beta_{0, s t}$, is equal to the component of total new taxes that is dependent on the value of state income, $\left(\Delta \beta_{1, s t} Y_{s, t-1}\right) .{ }^{24}$ Substituting (A3) into (A2) and doing some manipulation yields

$$
\text { Error }=\frac{-k_{s t}\left(1-\frac{Y_{s, t-1}}{Y_{s t}^{F}}\right)}{1+k_{s t}} .
$$

We now define a new variable, $g_{s t}$, such that

$$
Y_{s t}^{F}=\left(1+g_{s t}\right) \cdot Y_{s, t-1} \text {. }
$$

Thus, $g_{s t}$ is the forecasted annual growth rate of personal income. Substituting (A5) into (A4) and performing some algebraic manipulation yields

$$
\text { Error }=\frac{-k_{s t}\left(\frac{g_{s t}}{1+g_{s t}}\right)}{1+k_{s t}} .
$$

We are now in a position to estimate the size of the error. The annual growth rate of (nominal) state personal income from 1970 to 2000 is approximately 6 percent. Furthermore, it is unlikely that the changes in total taxes that were independent of income would ever be as large as the portion that is dependent on income. Accordingly, if we substitute "upper bound" values of $g_{s t}=0.10$ and $k_{s t}=1$, we get Error $=-0.045=-4.5$ percent. This constitutes the basis for our claim that "the error associated with measuring $\Delta$ Taxes $_{s t}^{\text {True }} / Y_{s, t-1}$ by $\Delta$ Taxes $_{s t}^{\text {Forecast }} / Y_{s t}$ when $\Delta \beta_{0, s t} \neq 0$ will generally be less than 5 percent."

\section{Notes}

1. Alternative names for this variable include average Tax Burden, average state tax rate, effective average state tax rate, and tax share.

2. Helms $(1985,577)$ argued that the use of Tax Burden to measure tax policy presents less severe problems compared with other feasible measures.

3. National Association of State Budget Officers (NASBO) estimates are reported in a series titled The Fiscal Survey of the States (National Governors' Association and NASBO 1987-2002). The latest estimates are available online at www.nasbo.org.

4. National Conference of State Legislatures (NCSL) estimates are published in State Budget Actions (1987-1989), State Budget and Tax Actions (1990-1991), and State Tax Actions (1992-2002). 
5. For example, if tax increases are phased in over a three-year period, the tax liability method shows three years of increases, whereas the baseline method only shows changes in the first year. Furthermore, if the legislature extends (postpones) a tax increase that was previously scheduled to expire (take effect), the tax liability method would indicate no change in taxes, while the baseline measure would indicate an increase (decrease). See State Tax Actions (NCSL 1996) for a comparison of the treatment of tax changes under both methods.

6. See Merriman (2000) for further discussions of the NASBO and NCSL estimates.

7. The Tax Burden variable used for these correlations is defined below.

8. Policy makers might want to overstate or understate expected revenues for various reasons including partisan politics (Rodgers and Joyce 1996). Some researchers stress the focus on minimizing the costs associated with inaccurate forecasts. Budget shortfalls cause cuts in program spending while surpluses can be seen as evidence of excessive tax rates or the underfunding of public goods (Feenberg et al. 1989).

9. Bretschneider and Gorr (1992) found that a complicated mix of partisan politics and fiscal stress factors drive forecast errors in sales tax revenues. In contrast, Mocan and Azad (1995) found no systematic bias in general fund revenues and little evidence of political and institutional influences as a whole.

10. Corroborating this interpretation are the similarities in the NASBO and NCSL estimates (cf. Figure 1), despite originating from organizations facing different political pressures.

11. For example, Tax Burden for 1996 would have tax revenues corresponding to fiscal year 1996 (which typically runs from July 1, 1995 through June 30, 1996) divided by personal income for calendar year 1995.

12. The NCSL-Taxpayer Liability (NCSL-TL) series is omitted because it is available for only a small number of years. 2001 is the most recent year for which Tax Burden could be calculated.

13. Figures representing Tax Burden time series for each state may be accessed via the Internet at http://faculty-staff.ou.edu/R/Cynthia.Rogers-1/TAX/TAXBURDEN.htm.

14. In Figure 4, Tax Burden for the United States is calculated as the ratio of the sum of state tax revenues for the United States over national personal income.

15. See, for example, Koester and Kormendi (1989) and Mullen and Williams (1994).

16. If state tax policy stays constant, then equation (5) implies that an increase in income (i.e., $\left.Y_{s t}>Y_{s, t-1}\right)$ will cause a decrease in Tax Burden in a state with a regressive tax structure $\left(\beta_{0, s t}>0\right)$.

17. Note that the NASBO/NCSL-collected forecasts consist solely of taxes, excluding fees.

18. $\Delta$ Taxes $_{s t}^{\text {Forecast }}$ is the same variable that Poterba (1994) called " $\triangle$ TAXNEXT $_{s t}$."

19. Note that the "next" year is $Y_{s t}$, since the budget forecast is made at the beginning of fiscal year $t$, which begins in the calendar year corresponding to $Y_{s, t-1}$.

20. The measurement error in $\Delta$ Taxes $_{s t}^{\text {Forecast }} / Y_{s t}$ stems from errors in forecasting next year's state income $\left(\varepsilon_{s t}^{F}\right)$. In contrast, the measurement error in $\Delta$ Tax Burden $_{s t}$ is due to changes in income as well as miscellaneous factors that are unrelated to state tax policy. These measurement errors have different consequences.

21. The reader may note that the error term in equation (11) includes the components $\varepsilon_{s, t+1}^{R} / Y_{s t}$ and $\varepsilon_{s t}^{R} / Y_{s, t-1}$, where $Y_{s t}$ and $Y_{s, t-1}$ also appear as explanatory variables in the second term. However, recall that $E\left(\varepsilon_{s t}^{R}\right)=0$ and is assumed to be uncorrelated with the income variable. 
22. Alaska, Hawaii, and Wyoming were omitted, the latter because its Tax Burden values, like Alaska's, have been greatly impacted by fluctuations in oil prices and production.

23. We also estimated specifications that added both state- and time-fixed effects to the NASBO- 1 and NCSL-1 models, but these were strictly dominated by the specifications with just time-fixed effects.

24. Strictly speaking, this should read "the component of total new taxes that is dependent on the value of state income assuming state income stays constant."

\section{References}

Becsi, Zsolt. 1996. Do state and local taxes affect relative state growth? Federal Reserve Bank of Atlanta Economic Review 81 (2): 18-36.

Bretschneider, Stuart, and Wilpen Gorr. 1992. Economic, organizational, and political influences on biases in forecasting state sales tax receipts. International Journal of Forecasting 7 (4): 457-66.

Feenberg, Daniel, William Gentry, David Gilroy, and Harvey Rosen. 1989. Testing the rationality of state revenue forecasts. Review of Economics and Statistics 71 (2): 300-308.

Fisher, Peter S., and Alan H. Peters. 1998. Industrial incentives: Competition among American states and cities. Kalamazoo, MI: W. E. Upjohn Institute for Employment Research.

Helms, Jay. 1985. The effect of state and local taxes on economic growth: A time series-cross section approach. Review of Economics and Statistics 67 (4): 574-82.

Koester, Reinhard B., and Roger C. Kormendi. 1989. Taxation, aggregate activity and economic growth: Cross-country evidence on some supply-side hypotheses. Economic Inquiry 27 (3): 367-86.

Maag, Elaine, and David Merriman. 2003. Tax policy responses to revenue shortfalls. Research Report. Washington, DC: Urban Institute.

Merriman, David. 2000. Economic conditions and state tax policy: Experience over the last decade and implications for the future. The Urban Institute Series A, No A-40. Washington, DC: Urban Institute.

- 2001. When do states legislate tax changes? In Proceedings: Ninety-third Annual Conference on Taxation, Santa Fe, New Mexico, and minutes of the annual meeting of the National Tax Association, Thursday, November 9, 2000;, 295-302. Washington, DC: National Tax Association.

Mocan, H. Naci, and Sam Azad. 1995. Accuracy and rationality of state general fund revenue forecasts: Evidence from panel data. International Journal of Forecasting 11 (3): 417-27.

Mullen, John, and Martin Williams. 1994. Marginal tax rates and state economic growth. Regional Science and Urban Economics 24 (6): 687-705.

National Conference of State Legislatures (NCSL). 1987-1989. Legislative finance paper: State budget actions. Denver, CO: NCSL.

1990-1991. State budget and tax actions. Denver, CO: NCSL.

1992-2002. State tax actions. Denver, CO: NCSL.

National Governors' Association and National Association of State Budget Officers (NASBO). 1987-2002. The fiscal survey of states. Washington, DC: NASBO.

Poterba, James M. 1994. State responses to fiscal crises: The effects of budgetary institutions and politics. Journal of Political Economy 102 (4): 799-821. 
Poterba, James M., and Kim S. Rueben. 2001. Fiscal news, state budget rules, and tax-exempt bond yields. Journal of Urban Economics 50 (3): 537-62.

Quantitative Micro Software. 2004. Eviews 5 user's guide. Irvine, CA: Quantitative Micro Software.

Reed, W. Robert, and Cynthia L. Rogers. 2003. A study of quasi-experimental control group methods for estimating policy impacts. Regional Science and Urban Economics 33 (3): 3-25.

2004. Tax cuts and employment growth in New Jersey: Lessons from a regional analysis. Public Finance Review 32 (3): 269-91.

Rodgers, Robert, and Philip Joyce. 1996. The effect of underforecasting on the accuracy of revenue forecasts by state governments. Public Administration Review, 56 (1): 48-56.

Tomljanovich, Marc. 2004. The role of state fiscal policy in state economic growth. Contemporary Economic Policy 22 (3): 318-30.

Wasylenko, Michael. 1997. Taxation and economic development: The state of the economic literature. New England Economic Review, March-April, 36-52.

Yamarik, Steven. 2000. Can tax policy help explain state-level macroeconomic growth? Economics Letters 68 (2): 211-15.

W. Robert Reed is a professor in the economics department at the University of Canterbury, New Zealand. His primary research focus is the effect of taxes on economic growth. His research has appeared in Cato Journal, Economic Inquiry, Economics and Politics, Journal of Human Resources, Journal of Labor Economics, Journal of Labor Research, Journal of Law, Economics, and Organization, Journal of Political Economy, Journal of Population Economics, Journal of Public Economics, Journal of Urban Economics, Public Finance Review, Public Choice, Regional Science and Urban Economics, Social Science Quarterly, and the Southern Economic Journal.

Cynthia L. Rogers is an associate professor in the economics department at the University of Oklahoma. Her research interests are state and local public finance and regional and urban economics. Her work has appeared in Economic Development Quarterly, International Regional Science Review, Journal of Labor Economics, Journal of Urban Economics, Public Finance Review, Regional Science and Urban Economics, and other journals. 